\title{
Pre-induction translabial ultrasound measurements in predicting mode of delivery compared to bishop score: a cross- sectional study
}

Soghra Khazardoost ${ }^{1}$, Fahimeh Ghotbizadeh Vahdani ${ }^{1,3^{*}}$, Sahar Latifi ${ }^{2}$, Sedighe Borna ${ }^{1}$, Maryam Tahani ${ }^{1}$, Mohammad Ali Rezaei ${ }^{2}$ and Masoomeh Shafaat ${ }^{2}$

\begin{abstract}
Background: By increased concerns about the accuracy of the traditional methods to predict outcomes after induction of labor, developing new standards has a great clinical importance. Here, we compared the predictive value of translabial ultrasound measurements with Bishop Score to determine the suitability of induction of labor.

Methods: A homogenous population of primigravid women was recruited. Induction of labor was performed with low-dose infusion of oxytocin. Translabial ultrasound and assessment of Bishop Score were performed by two different obstetricians. Receiver-operating characteristics curves were obtained to measure area under curve and subsequently, test sensitivity of each method.

Results: One hundred women entered the investigation. Maternal body mass index was significantly higher among candidates of Cesarean section (P: 0.02). Maternal age and fetus weight, gender and occiput position were not determinants of outcomes of induction of labor. Cervical length and fetal head-pubis symphysis distance measured by translabial ultrasound had a test sensitivity of 90 and $88 \%$, respectively which were slightly higher than sensitivity of Bishop score (84\%).

Conclusion: This study demonstrates that translabial measurements can be a suitable alternative method to monitor labor progress with an admissible predictive value compared with Bishop Score. It is a non-invasive method which provides valuable objective measurements and can be better accepted by women when considering the painful process which is required in evaluating Bishop Score.
\end{abstract}

Keywords: Ultrasound, Cesarean section, Bishop

\section{Background}

Although induction of labor (IOL) frequently occurs in term pregnancies, it has been demonstrated that it can be associated with higher rate of Cesarean section $(\mathrm{C} / \mathrm{S})$ $[1,2]$. Therefore, many investigations have tried to determine factors which are related to a successful vaginal delivery after IOL [3]. Fetal distress is the most common

\footnotetext{
* Correspondence: fghotbi@yahoo.com

${ }^{1}$ Department of obstetrics and gynecology, Vali-Asr hospital, Tehran University of Medical Sciences, Vali-Asr hospital, Imam Khomeini Hospital Complex, Keshavarz Boulevard, Tehran 1419733141, Iran

${ }^{3}$ Maternal, Fetal \& Neonatal Research Center, Vali-Asr hospital, Tehran University of Medical Sciences, Tehran, Iran

Full list of author information is available at the end of the article
}

reason for necessity of an operative delivery when IOL fails [4]. Identifying factors that can predict the success of IOL is clinically essential. Previously, Bishop Score has been used as the 'gold standard' predicting the suitability of IOL [5]. Bishop Score is measured by assessment of dilatation, effacement, consistency and position of the cervix and fetal station [5]. Since Bishop Score is a subjective measure, it can be accompanied with high intra- and inter-observer variability [6-11]. Moreover, the procedure of calculating Bishop Score is painful. By considering the limitations of Bishop Score the necessity of identification alternative measures to predict suitability of IOL is clear. 
Previously, Newman et al. [12] showed that Bishop Score predictive value is lesser than Cervical score at 26-29 weeks of pregnancy. Furthermore, some studies have shown that transvaginal ultrasound measurements perform better that Bishop Score [13-16]. However, conflicting results exist when addressing the comparison between Bishop Score and Ultrasound measurements $[17,18]$. Existence of these conflicting results emphasize on more research in this field especially with adjustment for other confounders to come to a proper comparison. Eggebø et al. [3] demonstrated that the predictive value of fetal head-perineum distance measured by transperineal ultrasound is similar to Bishop Score. However, since other factors such as parity and body mass index (BMI) are known to affect prediction of vaginal delivery after IOL [3], investigations on homogenous populations with considering the confounders were required to compare the predictive value of Bishop Score and ultrasound measurements.

In this study, only primigravid women were included and the predictive values of Bishop Score and translabial ultrasound measurements in determining suitability of IOL have been evaluated. Translabial ultrasound has been shown to be a suitable technique to assess labor [19].

\section{Methods}

\section{Study design and participants}

Participants were admitted women with term pregnancies in Tehran University Hospital. Inclusion criteria were: primigravity, term pregnancy with gestational age $>37$, healthy fetus with no detected anomalies, singleton fetus with cephalic presentation. Exclusion criteria were pre-term pregnancies, previous Cesarean section or other uterine surgeries, twin fetuses (multiple pregnancy), any suspicious finding of fetal distress at the time of admission. Women with gestational diabetes or suspicious findings indicating fetus macrosomia were excluded and only women with relatively similar range of fetus weight according to previous ultrasound examinations were recruited. Women with cephalopelvic disproportion detected in previously performed examinations were excluded as well. Total of 100 women were recruited in this prospective study. Written consent was obtained from each individual. Participation in the study was voluntary and those women with unwillingness to participate were considered as not eligible. Data was collected between 2012 and 2013.

The gestational age was determined based on the date of the last menstrual period and ultrasound measurements before 16 weeks of gestation. Labor arrest was defined based on Williams' Obstetrics criteria as arrest in cervical dilatation and fetus descends [20,21].

\section{Induction of labor (IOL)}

Labor was induced with low-dose oxytocin. The infusion of oxytocin was started at 1 mili unit per minute and was increased by 1-2 mili units per minute every 20 min until adequate uterine contraction was obtained [22]. Amniotomy was performed if the cervix was favorable (Bishop Score $\geq 6$ ). Successful IOL was defined as vaginal delivery regardless of the required time for its occurrence. Similar dosage and method were applied for all women to induce labor. For those patients with Bishop Score $<5,25 \mathrm{mg}$ Misoprostol was administered before IOL.

\section{Translabial ultrasound measurement}

Translabial Ultrasound was performed by using a Siemens ultrasound system with a five megahertz curved array transducer. The probe was positioned translabialy along with the following anatomical structures [23]: the pubic symphysis joint and the fetal skull. The transducer was placed in a way so that the symphysis was in horizontal position. All Ultrasound measurements were performed immediately after emptying the bladder and in supine position.

The fetal head-perineum distance was defined as the shortest distance between a line through the inferior posterior symphyseal margin (parallel to the main transducer axis) and the leading edge of the fetal skull. This measure is the distance from the outer bony limit of the fetal skull to the skin surface of the perineum [24]. Negative values were given when the presenting part was found cranial to the line of reference. Positive values imply that the head was seen beyond this line. Figure 1 shows the sonographic images in measuring cervical length and fetal head-symphysis pubic distance. Fetal head-pubis symphysis distance was measured according to the method described by Dietz et al. [23] Cervical length was measured by the same probe and at the same position, without any pressure to soft tissue [25]. Fetus entry angle and occiput position (anterior, transverse and posterior) were determined as well.

\section{Bishop score}

The Bishop score was assessed after performing ultrasound and immediately before IOL by another obstetrician who was blinded to the ultrasound measurements. Scoring was as follows: Position of cervix (posterior: 0 , intermediate: 1 , anterior: 2), consistency of the cervix (firm: 0 , intermediate: 1, soft: 2$)$, effacement (0-30 \%:0, 31-50 \%: 1, 51-80 \%: 2 , $>80 \%: 3)$, dilation (0 cm: $0,1-2 \mathrm{~cm}: 1,3-4 \mathrm{~cm}: 2,>5 \mathrm{cm:} 3)$, fetal station $(-3: 0,-2: 1,-1$ and $0: 2,+1$ and $+2: 3)$. A score $\leq 5$ suggests that labor is unlikely to start without induction. A score $\geq 9$ indicates that labor will most likely commence spontaneously [26]. 


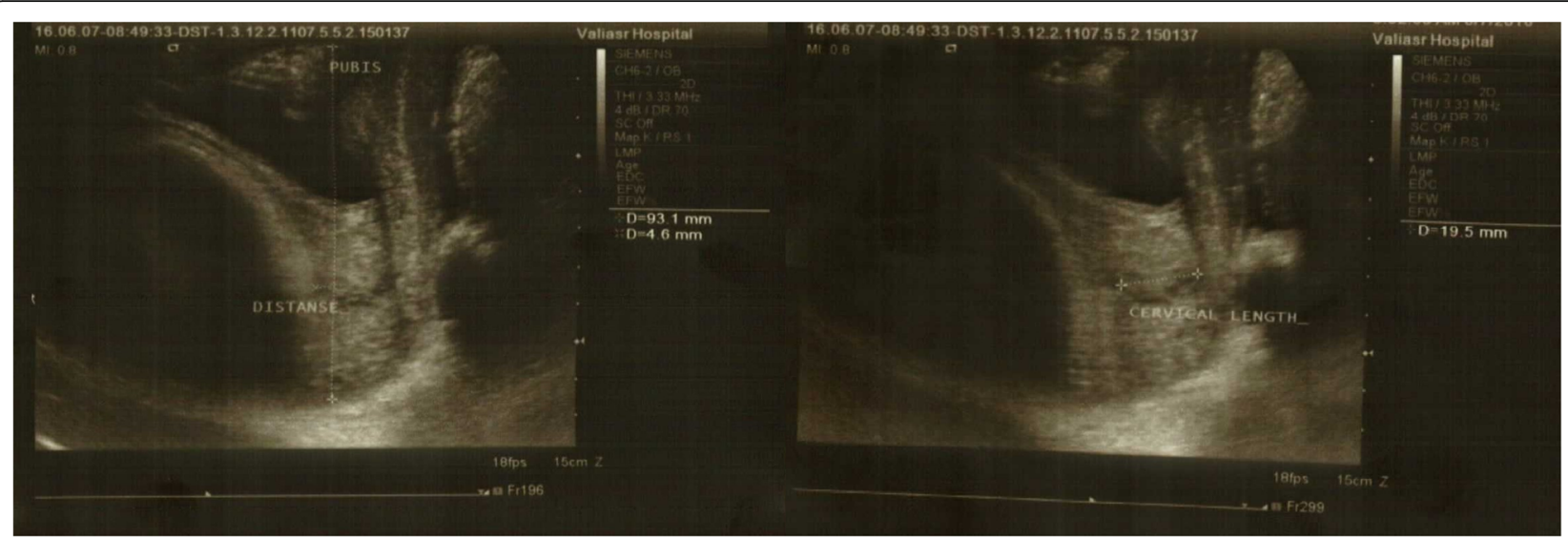

Fig. 1 Cervical length and fetal head-symphysis pubis distance as measured in sonographic images

\section{Statistical analysis}

All the statistical analysis was performed using SPSS version 21 (IBM corporation, USA). Categorical data are presented with percentages and continuous variables are presented with mean \pm standard deviation (SD). Comparison of categorical variables between groups (NVD and $\mathrm{C} /$ S) was performed using Pearson Chi-square and Fisher's Exact tests. One-way analysis of variance (ANOVA) was performed to compare means between groups. Partial correlation analysis with controlling for and BMI was used to assess the relationship between continuous variables. Multivariate analysis with adjustment for BMI was performed to assess the differences in continuous variables between groups (NVD vs. C/S). The predictive value of ultrasound measurements and Bishop Scores for a successful vaginal delivery was evaluated using receiver-operating characteristics (ROC) curves in which the area under the curve is used as discriminator to test the diagnostic performance of certain markers [3]. $P<0.05$ was considered statistically significant.

\section{Results}

One hundred women with mean age of $25.1 \pm 4.4$ years were enrolled. Table 1 shows the baseline characteristics of participants. Eighty nine women experienced the active phase of labor after IOL but only 57 participants had NVD and 43\%of patients needed Cesarean section $(\mathrm{C} / \mathrm{S})$. Eleven participants didn't enter the active phase and no changing was detected in the cervical dilatation progress, despite the adequate contraction of uterus. The indications of $\mathrm{C} / \mathrm{S}$ were fetal distress, thick meconium and non-favorable labor progression. Arrest in labor progression was identified as arrest in any stages even with a full cervical dilatation.

BMI before pregnancy and BMI at the time of IOL were significantly higher among those women who were candidate for C/S (P: 0.04 and 0.02 , respectively). There was no significant difference in the age between women
Table 1 Baseline maternal and fetal characteristics among participants with term pregnancy who were candidate for induction of labor

\begin{tabular}{|c|c|c|c|}
\hline Category & & $\begin{array}{l}\text { Number } \\
\text { (percentage) }\end{array}$ & Mean (SD) \\
\hline Age (years) & & & $25.13(4.4)$ \\
\hline Initial weight (kg) & & & $63.69(10.3)$ \\
\hline Initial BMI (kg/m²) & & & $24.12(3.4)$ \\
\hline Weight at the time of IOL (kg) & & & $76.04(1.1)$ \\
\hline $\mathrm{BMI}$ at the time of $\mathrm{IOL}\left(\mathrm{kg} / \mathrm{m}^{2}\right)$ & & & $28.80(3.7)$ \\
\hline Cervical length (mm) & & & $20.60(6.6)$ \\
\hline Fetus weight (gr) & & & 3334 (393.6) \\
\hline \multirow[t]{2}{*}{ Fetus gender } & Male & $46(46 \%)$ & \\
\hline & Female & $54(54 \%)$ & \\
\hline \multirow[t]{2}{*}{ Bishop score } & $\leq 5$ & 77 (77 \%) & \\
\hline & $>5$ & $23(23 \%)$ & \\
\hline $\begin{array}{l}\text { Time between IOL and initiation } \\
\text { of contractions (hour) }\end{array}$ & & & $2.0(1.1)$ \\
\hline $\begin{array}{l}\text { *Time between IOL and initiation } \\
\text { of cervical dilation (hour) }\end{array}$ & & & $2.14(0.8)$ \\
\hline $\begin{array}{l}\text { *Time between initiation of cervical } \\
\text { dilation to } 4 \mathrm{~cm} \text { dilation (hour) }\end{array}$ & & & $4.12(1.6)$ \\
\hline $\begin{array}{l}\text { *Time between cervical dilation of } \\
4 \mathrm{~cm} \text { to } 10 \mathrm{~cm} \text { (hour) }\end{array}$ & & & $4.60(1.5)$ \\
\hline $\begin{array}{l}\text { *Time between full cervical dilation } \\
\text { to labor (hour) }\end{array}$ & & & $3.12(2.7)$ \\
\hline \multirow[t]{2}{*}{ Delivery } & NVD & 57 (57 \%) & \\
\hline & $\mathrm{C} / \mathrm{S}$ & 43 (43 \%) & \\
\hline
\end{tabular}

BMI Body Mass Index, C/S Cesarean Section, IOL Induction of labor, NVD Normal vaginal delivery, SD Standard Deviation. *Time intervals between IOL and cervical dilations (to $4 \mathrm{~cm}$ and then to $10 \mathrm{~cm}$ ) are only measured for patients who had vaginal delivery. In patients who had inadequate progression of cervical dilation, $\mathrm{C} / \mathrm{S}$ was performed 
with NVD and those who needed C/S (P: 0.19). Bishop score was $\leq 5$ in $77 \%$ of term pregnancies (Table 1). Fetus gender and weight did not differ between NVD and C/S groups (P: 0.24 and 0.19). These outcomes showed that BMI can be considered as a factor which affects the progress of delivery whereas mode of delivery is not influenced by age, fetus gender and weight. Therefore further analyses were performed with adjustment for BMI.

Higher cervical length was detected among women who were candidate for C/S (P: 0.037). As expected, women with successful IOL had higher Bishop Score (P: 0.03). Another factor that determined the suitability of IOL was fetal head-pubis symphysis distance $(+3.00 \pm 2.5$ and -7.2 \pm 0.66 in NVD and C/S, respectively; P: 0.019) (Table 2). Apgar scores in all deliveries were 9 or 10. Among women who had successful vaginal delivery, fetus occiput position was anterior in $36.8 \%$, transverse in $47.4 \%$ and posterior in $15.8 \%$. Similarly, fetus occiput position was anterior in $28 \%$, transverse in $46.5 \%$ and posterior in $25.5 \%$ among candidates of C/S (Table 2). The fetus entry angle and the occiput position were not related to the type of delivery (P: 0.05 and 0.41, respectively).

The ROC curve showed an Area Under Curve (AUC) of $0.65(P=0.01)$ for fetal head-pubis symphysis distance and subsequently the sensitivity and specificity were measured to be around 88 and $70 \%$, respectively with cut off $12 \mathrm{~mm}$ for prediction of NVD.

AUC was $0.61(P=0.04)$ for Bishop Score with sensitivity and specificity of 84 and $70 \%$, respectively. Cutoff score for Bishop Score was 5. Bishop Score had slightly lower sensitivity compared with fetal head-pubis symphysis distance. AUC for cervical length measured by translabial ultrasound was 0.62 with sensitivity of $90 \%$, specificity of $65 \%$ and cutoff of $12.5 \mathrm{~mm}$ (Table 3 and Fig. 2). In Fig. 2 ROC curves for both modalities (defined based on mode of delivery) has been shown. As demonstrated in Fig. 2, the AUC of cervical length measured by ultrasound $(0.63, \mathrm{CI}$ : 0.49-0.71) is slightly higher than the AUC of Bishop Score (0.62, CI: 0.48-0.71). Both methods had admissible sensitivity and specificity in predicting mode of delivery.

\section{Discussion}

Ultrasound examination is a safe, quick and non-invasive method that has been shown to provide valuable objective measurements for monitoring progress of a labor [27]. Traditional methods observe labor progress by frequent examinations and assessment of Bishop Score. Recently, the use of ultrasound examinations is increasing to evaluate labor. However, there are limited literatures that have compared the value of ultrasound parameters with traditional examinations by assessing Bishop Score. With increasing concerns about the accuracy of Bishop Score and its value to determine the suitability of IOL, researches have emphasized on the necessity to develop alternative assessment standards [6-11]. Previously, Eggebø et al. [3] illustrated that fetal head-perineum distance measured by trans perineal ultrasound examination is a predictor of vaginal delivery after IOL with a similar predictive value compared with ultrasound-measured cervical length and the Bishop score. However, since it is well-established that parity is a strong predictor of successful IOL [14], further investigations on homogenous populations with similar parity were required

Table 2 Comparison of maternal and fetal factors between women with normal vaginal delivery after induction of labor and those who were candidate for Cesarean section. Analysis of the mean difference of cervical length, Bishop Score and fetal head-pubis symphysis distance was performed with multivariate analysis with adjustment for body mass index

\begin{tabular}{|c|c|c|c|c|c|c|}
\hline \multirow[t]{2}{*}{ Category } & & \multicolumn{2}{|l|}{ NVD (n: 57) } & \multicolumn{2}{|l|}{ C/S (n: 43) } & \multirow[t]{2}{*}{$P$-value } \\
\hline & & Number (Percentage) & Mean (SD) & Number (Percentage) & Mean (SD) & \\
\hline Age (years) & & - & $25.66(4.74)$ & - & $24.47(4.0)$ & 0.19 \\
\hline Initial BMI $\left(\mathrm{kg} / \mathrm{m}^{2}\right)$ & & - & $23.07(3.26)$ & - & $24.91(3.57)$ & $0.04^{*}$ \\
\hline $\mathrm{BMI}$ at the time of $\mathrm{IOL}\left(\mathrm{kg} / \mathrm{m}^{2}\right)$ & & - & $28.07(3.46)$ & - & $29.78(3.81)$ & $0.02^{*}$ \\
\hline Fetus weight (gr) & & - & $3378.9(306.9)$ & - & $3274.53(483.1)$ & 0.19 \\
\hline \multirow[t]{2}{*}{ Fetus gender } & male & $24(42.1 \%)$ & - & $22(51.2 \%)$ & - & \multirow[t]{2}{*}{0.24} \\
\hline & female & $33(57.9 \%)$ & - & $21(48.8 \%)$ & - & \\
\hline Cervical length (mm) & & - & $19.49(0.12)$ & - & $22.08(7.11)$ & $0.03^{*}$ \\
\hline Bishop Score & & - & $4.63(1.55)$ & - & $3.93(1.60)$ & $0.01^{*}$ \\
\hline Fetal head-pubis symphysis distance & & - & $+3.00(2.5)$ & - & $-7.2(0.66)$ & $0.01^{*}$ \\
\hline The fetus entry angle & & - & $90.10(9.18)$ & - & $85.04(11.0)$ & 0.05 \\
\hline \multirow[t]{3}{*}{ Fetus occiput position } & Anterior & $21(36.8 \%)$ & - & $12(28 \%)$ & - & \multirow[t]{3}{*}{0.41} \\
\hline & Transverse & 27 (47.4 \%) & - & $20(46.5 \%)$ & - & \\
\hline & Posterior & $9(15.8 \%)$ & - & $11(25.5 \%)$ & & \\
\hline
\end{tabular}

$B M I$ Body mass index, C/S Cesarean section, $I O L$ induction of labor, NVD Normal vaginal delivery, SD Standard deviation

* Significance at the level of $P<0.05$ 
Table 3 Ultrasound parameter and bishop score sensitivity and specificity

\begin{tabular}{|c|c|c|c|c|c|c|c|}
\hline Parameter & $A \cup C$ & Sensitivity & Specificity & Cut off & NPV & PPV & $P$-value \\
\hline Bishop score & 0.618 & $84 \%$ & $70 \%$ & 5 & $44 \%$ & $100 \%$ & $0.044^{*}$ \\
\hline Cervical length (mm) & 0.628 & $90 \%$ & $65 \%$ & 12.5 & $100 \%$ & $72 \%$ & $0.034^{*}$ \\
\hline Fetal head-pubis symphysis distance (mm) & 0.656 & $88 \%$ & $70 \%$ & 12 & $46 \%$ & $100 \%$ & $0.010^{*}$ \\
\hline
\end{tabular}

AUC Area under curve, NPV Negative predictive value, PPV Positive predictive value *Significance at the level of $P<0.05$

to come to a proper comparison of these methods. In this study, only primigravid women were included and our results showed that translabial ultrasound measurement can predict the suitability of IOL marginally better than Bishop Score. Test sensitivities were 88,90 and $84 \%$ for fetal head-pubis symphysis distance, cervical length and Bishop Score, respectively which indicates slightly better predictive value in ultrasound measurements. These findings confirm that ultrasound is a valuable non-invasive tool with a good diagnostic accuracy. By considering the low cost and reduced inter observer variability of ultrasound [28-33], this measurement tool can be recommended to be used routinely to monitor labor.

The superior predictive value of cervical length measured by trans-vaginal ultrasound compared with Bishop Score has been already demonstrated in previous studies [34-36]. However, since trans-vaginal ultrasound requires placing a vaginal probe, translabial ultrasound is better tolerated and accepted by most women. Here, we showed that translabial ultrasounds examination can also provide better and more reliable measurements for predicting labor compared with Bishop Score. Furthermore, it seems that extreme measures in both methods can predict the necessity of $\mathrm{C} / \mathrm{S}$ with similar value. In this regard, Tan et al. showed that a cervical length $>20 \mathrm{~mm}$ and bishop score $<5$ are independent predictors of $\mathrm{C} / \mathrm{S}$ [37].

Some investigations have proposed that measurement of fetus entry angle and occiput position may provide additional predictive values $[38,39]$. However, the predictive values of entry angel and occiput position have not been approved by other studies [40] which is may be due to recruitment of heterogeneous populations. To our knowledge, this is the first study on a homogenous population and our results confirm the superior value of ultrasound measurements including fetal head-pubis symphysis distance and cervical length in prediction of vaginal delivery after IOL. Furthermore, our results do not support the predictive value of entry angle and fetus occiput position on a homogenous population. Extreme measures of fetus weight including macrosomia have been shown to be associated with necessity of C/S [41] however in this study fetus weight was not a determinant of operative delivery which

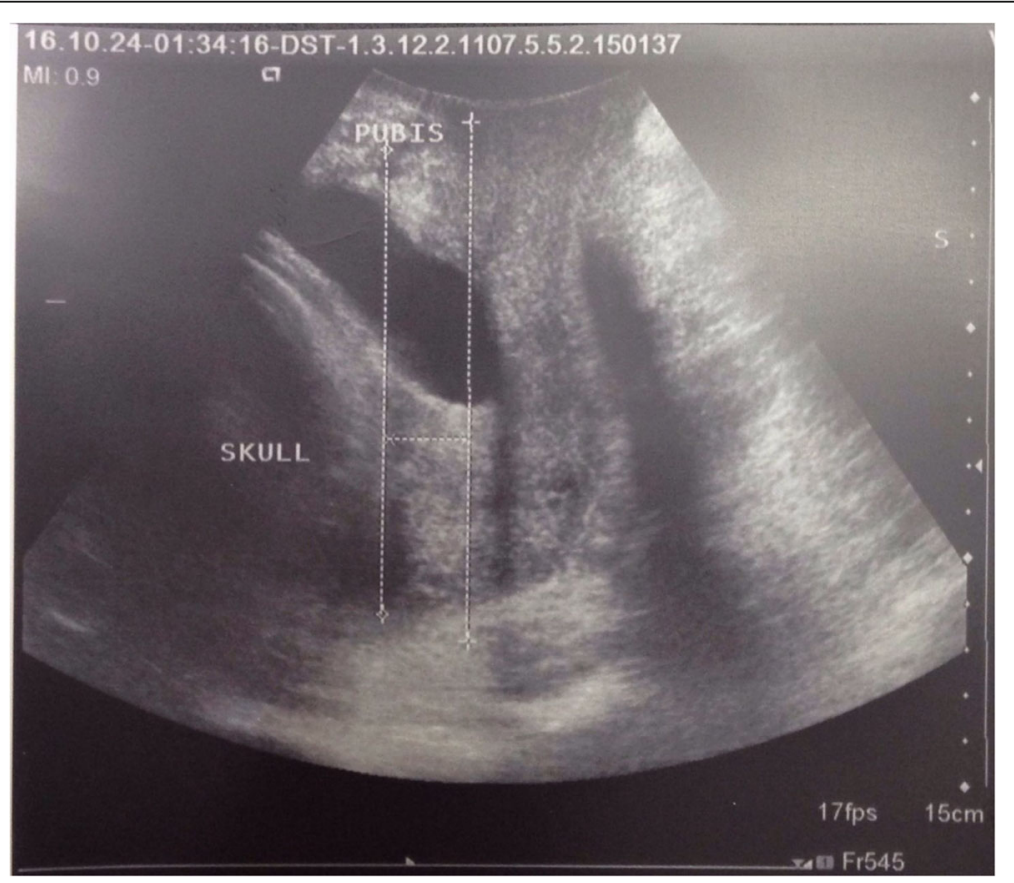

Fig. 2 Receiver-operating characteristics (ROC) curves of cervical length and fetal head-pubis symphysis distance measured by translabial ultrasound and Bishop Score 
is due to similar range of fetus weight among women with NVD and candidates of $\mathrm{C} / \mathrm{S}$. No beneficial effect of anterior occiput position could be detected in predicting successful IOL as well. It seems that clinical models with combined consideration of maternal factors and ultrasound measurements are needed for a proper prediction of successful vaginal delivery for each individual $[42,43]$.

In line with Eggebø et al. [3], our investigation did not confirm the predictive value of maternal age which conflicts with some other reports [13]. One reason for this difference can be the characteristics of the study population. Here, we only included primigravid women who have relatively similar ages and are younger than multiparous women. Previous investigations have tried to identify a model for combined consideration of maternal characteristics including age to predict outcome of IOL [44]. Further investigations with inclusion of various age groups and adjustment for other maternal confounders are required to determine the effect of age on labor.

The rate of delivery by Cesarean section in our department was $43 \%$ which is noticeably higher than Cesarean rate in Norway (13\%) [3] and is similar to Mexico (43.9\%), Italy (39.8 \%) and South Korea (35.3\%) [45]. There are many factors that affect this increasing Cesarean trend including socio-economic class [46], protocol of the related hospital [47] and increased technology [48]. It seems that the characteristics of population in each nation affect the rate of $C / S$. Therefore, more investigations are required to determine the Iranian population features to clarify the reasons behind this high rate of $\mathrm{C} / \mathrm{S}$.

This study shows that translabial ultrasound can predict the successful vaginal delivery after induction of labor better than Bishop Score. Cervical length and fetal head-pubis symphysis distance measured by translabial ultrasounds have admissible test sensitivity of $90 \%$ and $88 \%$, respectively. This method is safe, non-invasive and provides valuable objective measures to predict suitability of induction of labor. Translabial ultrasound can be better accepted by women when considering the painful process of assessing Bishop Score. Moreover, by considering the reduced risk of infection by using ultrasound measurements especially in case of rupture of the amniotic sac, translabial ultrasound is suggested to be routinely used to monitor the progress of the labor.

\section{Conclusion}

In this investigation, the predictive values of Bishop Score and translabial ultrasound measurements in determining suitability of IOL have been evaluated. This study demonstrates that translabial measurements can be a suitable alternative method to monitor labor progress with an admissible predictive value compared with Bishop Score. It is a non-invasive method which provides valuable objective measurements and can be better accepted by women when considering the painful process which is required in evaluating Bishop Score.

\section{Study limitation}

This study suggests that ultrasound measurement be considered as a routine examination to monitor the progression of the labor in clinical practice. Subsequently, the need for the skillful staff to perform ultrasound and to render accurate sonographic measurements increases which should be taken into consideration.

\section{Acknowledgement}

We like to thank all the staff that helped us in patient management during performing this study.

\section{Funding}

The study was basically funded by authors themselves. There were no external sponsors.

\section{Availability of data and materials}

Data has been collected in Vali-Asr Hospital, Imam Khomeini hospital affiliated to Tehran University of Medical Sciences. The classified and organized databases as the source of data for this study can be found at the study data registry of this hospital.

\section{Authors' contributions \\ SK contributed to the study design and data collection, FG contributed to data collection and performing the study, SL contributed to perform the statistical analysis and wrote the primary draft of the manuscript, SB contributed data collection, MT contributed to the data collection, MAR contributed to intellectual editing of the manuscript and data interpretation and MS contributed to the data collection. All authors read and approved the final manuscript.}

competing interests

All authors declare to have no competing interests regarding this study.

\section{Consent for publication}

This manuscript does not contain any individual person's data in any form.

\section{Ethics approval and consent to participate}

The study protocol was approved by ethics committee of Tehran University of Medical Sciences. All authors declare to have no conflicts of interest. No secondary analysis of existing data has been performed.

\section{Author details}

${ }^{1}$ Department of obstetrics and gynecology, Vali-Asr hospital, Tehran University of Medical Sciences, Vali-Asr hospital, Imam Khomeini Hospital Complex, Keshavarz Boulevard, Tehran 1419733141, Iran. ${ }^{2}$ Tehran University of Medical Sciences, Tehran, Iran. ${ }^{3}$ Maternal, Fetal \& Neonatal Research Center, Vali-Asr hospital, Tehran University of Medical Sciences, Tehran, Iran.

Received: 10 October 2015 Accepted: 22 September 2016

Published online: 28 October 2016

\section{References}

1. Maslow AS, Sweeny AL. Elective induction of labor as a risk factor for cesarean delivery among low-risk women at term. Obstet Gynecol. 2000;95(6 Pt 1):917-22.

2. Heffner $L$, Elkin $E$, Fretts RC. Impact of labor induction, gestational age, and maternal age on cesarean delivery rates. Obstet Gynecol. 2003;102(2):287-93.

3. Eggebø TM, Heien C, Økland I, Gjessing LK, Romundstad P, Salvesen KA. Ultrasound assessment of fetal head-perineum distance before induction of labor. Ultrasound Obstet Gynecol. 2008;32(2):199-204.

4. Crowley P. Interventions for preventing or improving the outcome of delivery at or beyond term. Cochrane Database Syst Rev. 2000;2:CD000170.

5. Bishop EH. Pelvic scoring for elective induction. Obstet Gynecol. 1964;24:266-8.

6. Jackson GM, Ludmir J, Bader TJ. The accuracy of digital examination and ultrasound in the evaluation of cervical length. Obstet Gynecol. 1992;79(2):214-8. 
7. Holcomb Jr WL, Smeltzer JS. Cervical effacement: Variation and belief among clinicians. Obstet Gynecol. 1991;78(1):43-5.

8. Buchmann E. libhaber E. Interobserver agreement in intra partum estimation of fetal head station. Int J Gynecol Obstet. 2008;101(3):285-9.

9. Dupuis O, Silveira R, Zentner A, Dittmar A, Gaucherand P, Cucherat M, et al. Birth simulator: reliability of transvaginal assessment of fetal head station as defined by the American College of Obstetricians and Gynecologists classification. Am J ObstetGynecol. 2005;192(3):868-74.

10. Sadoul G, Beuret T, Lewin D. The different elements constituting the Bishop score in the induction of labor with epidural analgesia. J Gynecol Obstet Biol Reprod (Paris). 1981;10(3):269-73.

11. Faltin-Traub EF, Boulvain M, Faltin DL, Extermann P, Irion O. Reliability of the Bishop score before labor induction at term. Eur J Obstet Gynecol Reprod Biol. 2004;112(2):178-81.

12. Newman RB, Goldenberg RL, lams JD, Meis PJ, Mercer BM, Moawad AH, et al. Preterm prediction study: comparison of the cervical score and Bishop score for prediction of spontaneous preterm delivery. Obstet Gynecol. 2008;112(3):508-15.

13. Rane SM, Guirgis RR, Higgins B, Nicolaides KH. Models for the prediction of successful induction of labor based on pre-induction sonographic measurement of cervical length. J Matern Fetal Neonatal Med. 2005;17(5):315-22.

14. Rane SM, Pandis GK, Guirgis RR, Nicolaides KH. Pre-induction sonographic measurement of cervical length in prolonged pregnancy: the effect of parity in the prediction of the need for Cesarean section. Ultrasound Obstet Gynecol. 2003;22(1):40-4

15. Rane SM, Guirgis RR, Higgins B, Nicolaides KH. The value of ultrasound in the prediction of successful induction of labor. Ultrasound Obstet Gynecol. 2004;24(5):538-49.

16. Laencina AM, Sanchez FG, Gimenez JH, Martinez MS, Martinez JA, Vizcaino VM. Comparison of ultrasonographic cervical length and the Bishop score in predicting successful labor induction. Acta Obstet Gynecol Scand. 2007:86(7):799-804.

17. Rozenberg P, Chevret S, Chastang C, Ville Y. Comparison of digital and ultrasonographic examination of the cervix in predicting time interval from induction to delivery in women with a low Bishop score. BJOG. 2005:112(2):192-6.

18. Rozenberg P, Chevret S, Ville Y. Comparison of pre-induction ultrasonographic cervical length and Bishop score in predicting risk of cesarean section after labor induction with prostaglandins. Gynecol Obstet Fertil. 2005;33(1-2):17-22.

19. Tutschek B, Braun T, Chantraine F, Henrich W. A study of progress of labor using intrapartumtranslabial ultrasound, assessing head station, direction, and angle of descent. BJOG. 2011;118(1):62-9.

20. Friedman E. The graphic analysis of labor. Am J Obstet Gynecol. 1954:68(6):1568-75.

21. Cunningham FG, Leveno K, Bloom S, Spong CY, Dashe J. Williams Obstetrics. 24th ed. 2014. p. 456.

22. ACOG Committee on Practice Bulletins - Obstetrics. ACOG Practice Bulletin No. 107: Induction of labor. Obstet Gynecol. 2009:114(2 Pt 1):386-97.

23. Ho D, Lanzarone V. Measuring engagement of fetal head: validity and reproducibility of a new ultrasound technique. Ultrasound Obstet Gynecol. 2005;25(2):165-8

24. Eggebø TM, Gjessing LK, Heien C, Smedvig E, Økland I, Romundstad P, et al. Prediction of labor and delivery by trans perineal ultrasound in pregnancies with prelabor rupture of membranes at term. Ultrasound Obstet Gynecol. 2006;27(4):387-91.

25. Valentin L, Bergelin I. Intra- and interobserver reproducibility of ultrasound measurements of cervical length and width in the second and third trimesters of pregnancy. Ultrasound Obstet Gynecol. 2002;20(3):256-62.

26. Tenore J. Methods for cervical ripening and induction of labor. Am Fam Physician. 2003;67(10):2123-8.

27. Sherer DM. Intrapartum ultrasound. Ultrasound Obstet Gynecol. 2007:30(2):123-39.

28. Sherer DM, Miodovnik M, Bradley KS, Langer O. Intrapartum fetal head position II: comparison between transvaginal digital examination and trans abdominal ultrasound assessment during the second stage of labor. Ultrasound Obstet Gynecol. 2002;19(3):264-8.

29. Sherer DM, Miodovnik M, Bradley KS, Langer O. Intrapartum fetal head position l: comparison between trans vaginal digital examination and trans abdominal ultrasound assessment during the active stage of labor. Ultrasound Obstet Gynecol. 2002;19(3):258-63.
30. Kreiser D, Schiff E, Lipitz S, Kayam Z, Avraham A, Achiron R. Determination of fetal occiput position by ultrasound during the second stage of labor. J Maternal fetal Med. 2001;10(4):283-6.

31. Akmal S, Tsoi E, Kametas N, Howard R, Nicolaides KH. Intrapartum sonography to determine fetal head position. J Matern Fetal Neonatal Med. 2002;12(3):172-7.

32. Akmal S, Kametas N, Tsoi E, Hargreaves C, Nicolaides KH. Comparison of transvaginal digital examination with intrapartum sonography to determine fetal head position before instrumental delivery. Ultrasound Obstet Gynecol. 2003;21(5):437-40

33. Souka AP, Haritos T, Basayiannis K, Noikokyri N, Antsaklis A. Intrapartum ultrasound for the examination of the fetal head position in normal and obstructed labor. J Matern Fetal Neonatal Med. 2003:13(1):59-63.

34. Gabriel R, Darnaud T, Chalot F, Gonzalez N, Leymarie F, Quereux C. Transvaginal sonography of the uterine cervix prior to labor induction. Ultrasound Obstet Gynecol. 2002;19(3):254-7.

35. Ware V, Raynor BD. Transvaginal ultrasonograpic cervical measurement as a predictor of successful labor induction. Am J Obstet Gynecol. 2000;182(5):1030-2.

36. Uyar Y, Erbay G, Demir BC, Baytur Y. Comparison of the Bishop Score body mass index and Transvaginal cervical length. Arch Gynecol Obstet. 2009;280(3):357-62.

37. Tan P, Cvallikkunnu N, Sugunas, Quek KF, Hassan J. Transvaginal sonographic measurement of cervical length vs. Bishop score in labor induction at term: tolerability and prediction of Cesarean delivery. Ultrasound Obstet Gynecol. 2007;29(5):568-73.

38. Bartha JL, Romero-Carmona R, Martinez-Del-Fresno P, Comino-Delgado R. Bishop score and transvaginal ultrasound for preinduction cervical assessment: a randomized clinical trial. Ultrasound Obstet Gynecol. 2005;25(2):155-9.

39. Pandis GK, Papageorghiou AT, Ramanathan VG, Thompson MO, Nicolaides $\mathrm{KH}$. Preinduction sonographic measurement of cervical length in the prediction of successful induction of labor. Ultrasound Obstet Gynecol. 2001;18(6):623-8.

40. Gonen R, Degani S, Ron A. Prediction of successful induction of labor: comparison of transvaginal ultrasonography and the Bishop score. Eur J Ultrasound. 1998;7(3):183-7.

41. Mikulandra F, Persia M, Stojnic E. When is fetal macrosomia (> or $=4500 \mathrm{~g}$ ) an indication for caesarean section? Zentralbl Gynakol. 1996;118(8):441-7.

42. Peregrine E, O'Brien P, Omar R, Jauniaux E. Clinical and ultrasound parameters to predict the risk of cesarean delivery after induction of labor. Obstet Gynecol. 2006;107(2 Pt 1):227-33.

43. Dietz HP, Lanzarone V, Simpson JM. Predicting operative delivery. Ultrasound Obstet Gynecol. 2006;27(4):409-15.

44. Nader R, Shek KL, Dietz HP. Predicting the outcome of induction of labor. Aust N Z J Obstet Gynaecol. 2010;50(4):329-33.

45. Niino $Y$. The increasing cesarean rate globally and what we can do about it. Biosci Trends. 2011:5(4):139-50

46. Arrieta A. Health reform and cesarean sections in the private sector: The experience of Peru. Health Policy. 2010;99(2):124-30.

47. Hamilton BE, Martin JA, Ventura SJ. Births: Preliminary Data for 2009 Natl Vital Stat Rep. 2010:59(3):1-14.

48. Stafford RS. Cesarean section use and source of payment: An analysis of California hospital discharge abstracts. Am J Public Health. 1990;80(3):313-5.

\section{Submit your next manuscript to BioMed Central and we will help you at every step:}

- We accept pre-submission inquiries

- Our selector tool helps you to find the most relevant journal

- We provide round the clock customer support

- Convenient online submission

- Thorough peer review

- Inclusion in PubMed and all major indexing services

- Maximum visibility for your research

Submit your manuscript at www.biomedcentral.com/submit 